Until unequivocal evidence is provided from well-conducted concurrently controlled trials the case for immunotherapy in malignant melanoma will remain unproved. No amount of optimistic speculation or vague assertion will convert a promising but nebulous idea into a realistic method of treatment.

${ }^{1}$ Levene, A, Fournal of Clinical and Experimental Dermatology, 1976, 1, 17.

2 Clark, W H, et al, Cancer Research, 1969, 29, 705.

${ }^{3}$ British Medical fournal, 1976, 1, 1487.

4 McKneally, M F, Maver, C, and Kausel, H W, Lancet, 1976, 1, 377.

${ }^{5}$ Compendium of Tumour Immunotherapy Protocols No 3 International Registry of Tumour Immunology. Bethesda, National Institutes of Health, 1976.

${ }^{6}$ Gutterman, J U, et al, Cancer Immunology and Immunotherapy, 1976, 1, 99. 7 Morton, D L, et al, Cancer Immunology and Immunotherapy, 1976, 1, 93. ${ }^{8}$ Currie, G A, and McElwain, T J, British fournal of Cancer, 1975, 31, 143. 9 Newlands, E S, et al, British fournal of Cancer, 1976, 34, 174.

\section{Chemotherapy in breast cancer}

The term "breakthrough" applied to cancer therapy has become so commonplace that an intelligent lay person might be forgiven for expressing surprise that patients continue to die of this disease. A good example of the media overreacting to an undoubted important contribution to cancer therapy has been the reception afforded two recent papers on the use of adjuvant chemotherapy for early breast cancer. ${ }^{12}$ The muted acclaim with which these articles were received by the profession has been transformed into a triumphant fanfare by the popular media in the USA, and even the serious Sunday newspapers ${ }^{34}$ and the radio in Britain. ${ }^{5} \mathrm{~A}$ distinguished spokesman for the National Cancer Institute went so far as to state on a BBC 4 programme that $98 \%$ of women who had disseminated breast cancer at the time they had been put under treatment were being kept alive without recurrence of the disease. 5

As a result of this kind of sensationalism clinicians in America are being placed in an impossible position. Patients and referring practitioners are now putting pressure on surgeons to give the new wonder cure, and in the climate of defensive medicine practised on the other side of the Atlantic such pressure may be difficult to resist. There are now early signs that this unfortunate state of affairs may have crossed to Europe. The statement by the British Breast Group (see p 861) on the current status of adjuvant chemotherapy in early breast cancer is, therefore, both timely and important. This authoritative report may go a long way towards checking the premature adoption of what must be considered still to be an experimental mode of treatment. Also relevant is the recent paper by Costanza ${ }^{6}$ which gave four reasons for advocating extreme caution in the premature application of chemoprophylaxis in breast cancer. Firstly, the drugs used are immunosuppressive, and chronic immunosuppression is associated with the risk of the development of other cancers. ${ }^{7}$ Secondly, the alkylating agents in these adjuvant programmes are also known to be carcinogenic, and there have now been reports of the development of second solid tumours ${ }^{8}$ or leukaemia $^{9}$ in patients on long-term chemotherapy for malignant disease. Thirdly, the drugs have myelosuppressive properties, making them dangerous and potentially lethal in inexperienced hands. There are not enough medical oncologists in Britain to provide a chemotherapy service for every surgeon treating breast cancer. Finally, she reminds us that in as many as a third of patients with diseased lymph nodes chemoprophylaxis given on statistical grounds alone might be unnecessary-these patients would have escaped recurrent disease. While nodal status is the best prognostic indicator yet available, we still need to remember that the ideal index has yet to be described.

None the less, most workers on breast cancer believe that important improvements in survival after local removal of the diseased tissues are likely to be achieved only by some form of systemic therapy to attack the micrometastases present in so many women with apparently localised disease. There are, however, less toxic forms of treatment available that have not yet been adequately tested-a point emphasised by Stoll, who has argued ${ }^{10}$ for well-designed trials of endocrine treatment at the time of mastectomy. The results of adjuvant chemotherapy from the NSABP ${ }^{1}$ and the Milan group ${ }^{2}$ have yet to show any significant improvement in survival in the group receiving additive therapy. So to anticipate the pressures that clinicians could face from an "informed general public," we can only echo Costanza's statement that "Until the ultimate value and risks are known, chemoprophylaxis should not be regarded as standard procedure." For the time being at least clinicians should stick to what they would consider conventional treatment, or alternatively enter their patients into one of the current trials evaluating adjuvant chemotherapy.

${ }^{1}$ Fisher, B, et al, New England fournal of Medicine, 1975, 292, 117.

2 Bonadonna, G, et al, New England fournal of Medicine, 1976, 294, 405.

3 Observer, 22 February 1976.

4 Sunday Times, 20 June 1976.

${ }^{5}$ BBC 4, 7 July 1976.

${ }^{6}$ Costanza, M E, New England fournal of Medicine, 1975, 293, 1095.

7 Penn, I, Cancer, 1974, 34, 858.

${ }^{8}$ Canellos, G P, et al, Recent Results Cancer Research, 1974, 49, 108.

${ }^{9} \mathrm{Kyle}, \mathrm{R}$ A, Pierre, R V, and Bayrd, E D, Archives of Internal Medicine, $1975,135,185$.

${ }^{10}$ Stoll, B, unpublished.

\section{Screening for breast cancer}

In 1973 breast cancer killed almost 11500 women in England and Wales and there is evidence that mortality from the disease is increasing, especially among those aged 45-64 years. ${ }^{1}$ Despite this, recent reports from two areas of research provide grounds for cautious optimism.

Firstly, two groups of workers ${ }^{2} 3$ have published results suggesting that systemic chemotherapy may be of value in the treatment of early breast cancer. Too much should not be made of their findings, which have been put into perspective by the statement by the British Breast Group (p 861) and the leading article on this page; but this new approach has lifted morale.

The second encouragement comes from the seven-year follow-up figures of the well-known Health Insurance Plan (HIP) trial in New York. ${ }^{4}$ These showed a $35 \%$ reduction in the number of deaths from breast cancer in the group offered annual screening examinations when compared with the control group, which received only normal medical care. This benefit, however, was confined to those aged over 50 years.

While the HIP trial remains the only study capable of providing information about the effect of screening on mortality the results of a number of smaller uncontrolled investigations are also proving of value. When screening has been offered to clearly defined groups of women the acceptance rates have 